\title{
PREVENTON OF CHILDHOOD DIABETES IN SCHOOL ENVIRONMENT: AWARENESS OF FAMILIES
}

\author{
Mariana Zhelyazkova $^{1}$, Silvia Borisova ${ }^{2}$, Ivan Dimitrov ${ }^{1}$ \\ 'Sliven Affiliate, Medical University of Varna, \\ ${ }^{2}$ Department of Health Care, Faculty of Public Health, Medical University of Varna
}

\begin{abstract}
INTRODUCTION: Diabetes is the most common metabolic disease in school-age children. The families of these children need information about the specifics of the disease. Given the incidence rate of the disease on one hand, and factors such as the trend for unhealthy eating habits in children and the decrease in physical activity, on the other, prevention should play a key role when working with parents. This could be of great importance for the decrease of the morbidity rate. Thus, support for the parents by healthcare professionals would be appropriate in the school environment.
\end{abstract}

AIM: To assess the knowledge of families about diabetes in school-age children, and to promote the prevention and prophylaxis of the disease with the involvement of nurses.

MATERIALS AND METHODS: A survey has been conducted amongst parents of school children. The level of awareness about the disease and the needs of the families have been assessed.

RESULTS: Families are not always educated well enough about diet (68\%), physical activity (43\%), and the role of heredity $(48 \%)$ as a factor in the development of diabetes. The most trusted healthcare professionals are usually the school nurse, the family physician and the psychologist.

CONCLUSION: The support with regard to prevention of diabetes would facilitate the families and will aid in improving the lifestyle of school-age children. The data from our study reveal the level of awareness of families regarding diabetes in school environment and stimulate support to prevent the disease.

Keywords: awareness, family, support, diabetes, school, nurse

\section{INTRODUCTION}

Diabetes is the most common metabolic disease in school-age children. The families of these children need information about the specifics of the disease. Given the incidence rate of the disease on one hand, and factors, such as the tendency towards unhealthy eating habits in children and decreased physical activity, on the other, prevention should play a

Address for correspondence:

Mariana Zhelyazkova

Sliven Affiliate

Medical University of Varna

30 Gen. Stoletov St

Sliven

e-mail:marijel61@abv.bg key role when working with parents. This would be of great importance for the decrease of the morbidity rate. Thus, it would be appropriate for healthcare professionals to provide support for parents within the school environment. They need support, understanding and information about the care needed when living with diabetes, as well as information about prevention. This is a key factor for the decrease of the morbidity rate, and involves the participation of healthcare professionals (2).

In this sense, it would be useful to investigate the awareness of parents about developing diabetes in school-age children. The level of awareness will help them promote an appropriate diet and increased physical activity for disease prevention (1). In 
the process of prevention, the specific role of educating is played by the nurse, who is a factor in the communication with the family in terms of health management (3).

\section{AIM}

Supporting the families of the children in a school environment for diabetes prevention and prophylaxis requires the participation of the nurse. Part of our goal was to determine the level of awareness of parents of school-age children in regard to the risk factors for the occurrence of diabetes and the opportunities for prevention.

Study Objectives:

$\diamond$ to study the level of awareness among parents about the prerequisites for the occurrence of diabetes;

$\diamond$ to study the understanding of parents about the appropriate diet, physical activity, and prevention of diabetes in children;

$\diamond$ to collect information about the confidence in healthcare professionals /nurses/ via communication with parents of school-age children.

\section{MATERIALS AND METHODS}

Information from a survey among parents of school-age children from the town of Sliven has been used. The level of awareness of the families with regard to diet, physical activity and the role of heredity as a factor in developing diabetes have been assessed. The survey has been conducted through forms with open- and closed-ended questions, with a limited number of participants: 40 parents of schoolage children diagnosed with type 2 diabetes, and 38 parents of healthy school-age children. Data has been presented in tables and figures.

\section{RESULTS}

Out of the 40 parents asked whether they know any children suffering from diabetes, $30 \%$ answered negatively, $2 \%$ of the answers were positive, and 8 of the parents asked were not aware about diabetes in children and its prevention.

The current aspects of improving the care for school-age children with diabetes and the options for prevention include the involvement of a healthcare professional who evokes confidence for being com- petent. The nurse in the school office can be such an example.

The parents of healthy children often share the need of increasing their awareness about prevention of diabetes, such as the proper diet and physical activity for the child, understanding of healthy food, and stress management in daily life. They believe that a healthcare professional would be informed well enough on the matters and would be capable of providing reliable facts.

Participants report that knowledge about diabetes is acquired mainly from the healthcare professional/nurse at school.

The families are not always educated well enough about diet $-68 \%$ of the surveyed sample, or 29 parents, are not informed and only 11 of them (32\%) think that they are informed (Fig. 1).

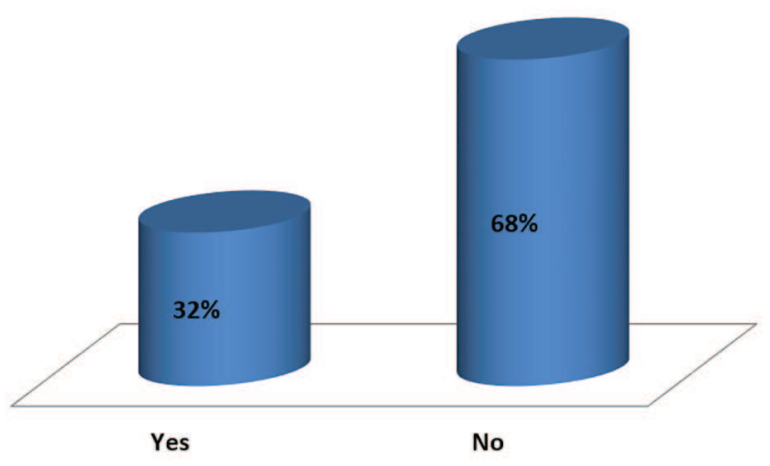

Fig. 1. Parents: information about diet

Sixty-eight percent of the parents do not take any steps towards educating children with regard to keeping and improving their own health. They do not have negative attitude towards unhealthy foods,

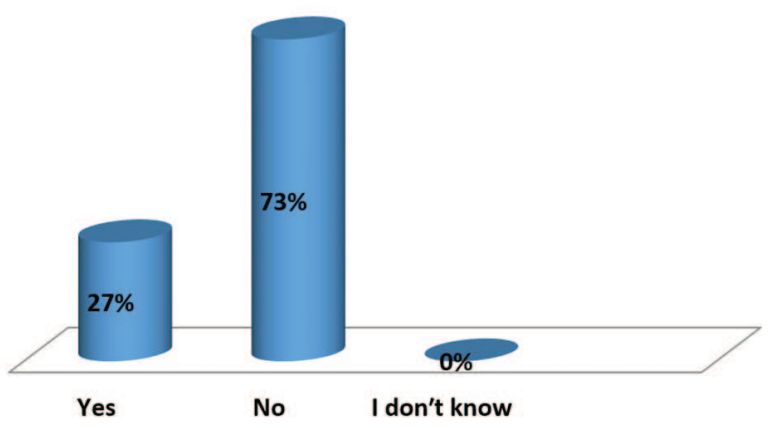

Fig. 2. Parents: applying a specific diet in children 
Mariana Zhelyazkova, Silvia Borisova, Ivan Dimitrov

do not develop proper skills to choose the right foods and prepare the daily diet.

Only $27 \%$ of the parents asked have knowledge and can introduce their children to the principles of healthy eating. The group of those informed about a rational diet includes the parents of children diagnosed with diabetes (5\%). The other $73 \%$ of the parents do not suggest any diets to their children (Fig. 2).

When asked if the child has any physical activity for at least 30 minutes a day, $43 \%$ of the parents answer negatively /17 parents/, 30\% /12 parents/ answer positively, and the other $27 \% / 11 /$ do not know (Fig. 3).

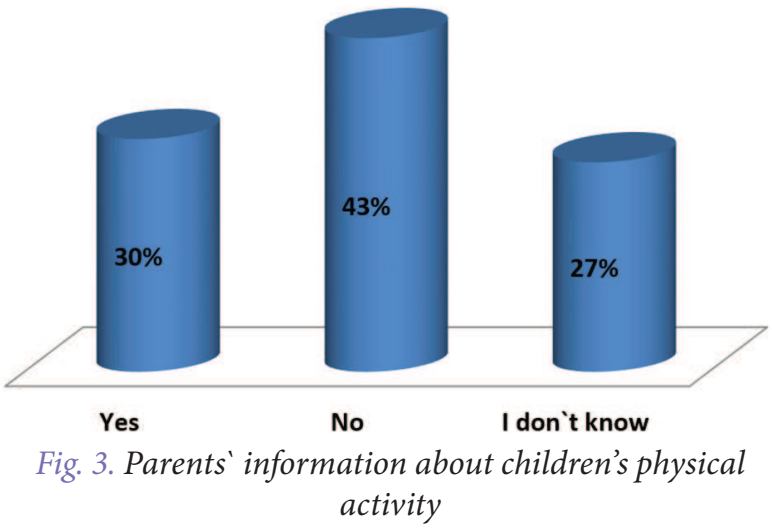

The role of the heredity is not considered a factor for developing diabetes by $48 \%$ (17) of the parents questioned, $50 \%$ know about the genetic factor in the risk of developing diabetes (20 parents) and $2 \%$ do not have an answer (3 parents) (Fig. 4).

When asked about the desire for education and topics related to diabetes, the highest percentage

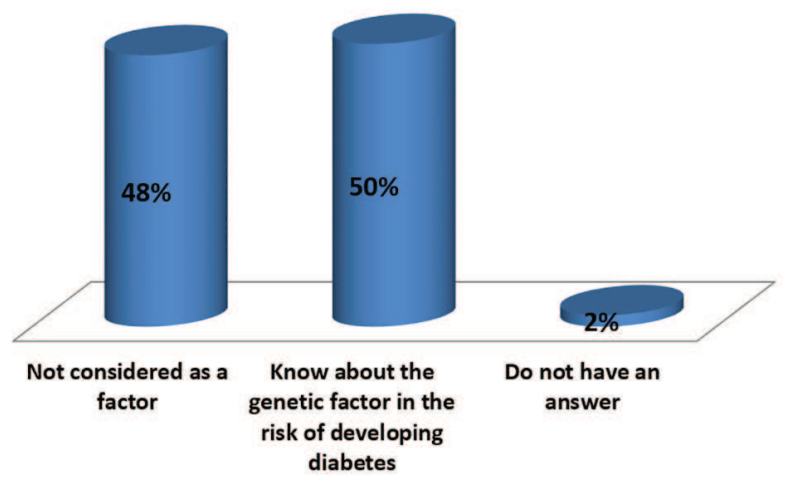

Fig. 4. Parents' information about the role of heredity as a factor for developing diabetes showed interest in the ways to reduce obesity (83\%) and how to react in specific situations (17\%).

The information collected about the need for a professional who can be trusted by the parents and the school-age children, strengthens the role of the nurse at school. This raises the expectations with regard to proper behavior and keeping children's health in the school age. The purpose of the question about the received support is similar, where the nurse and the psychologist get $88.8 \%$ of the answers of those questioned.

\section{DEDUCTION}

Diabetes is a well-known disease, however, the awareness of the parents asked about its development in school environment is inadequate.

The families may not always be informed well enough about healthy eating, physical activity, and the role of heredity as a factor in developing diabetes. The most trusted healthcare professionals in the prevention of diabetes are usually the school nurse, the family physician and the psychologist.

Supporting the parents of school-age children is a good way of assuring practical results in order to increase the awareness of families about preventive healthcare in children. The data for the territory of Sliven region show that the parents need specialized support by healthcare professionals/nurses in the care for children with diabetes. The level of awareness with regard to diet and physical activity in the school age is inadequate. The involvement of nurses would provide positive results and would stabilize the general state of children with regard to care and prevention.

\section{CONCLUSION}

The support directed to prevention of diabetes would facilitate the families and would aid them in improving the lifestyle of school-age children. The data from our study reveal the level of awareness of the families with regard to diabetes in the school environment, and the ways of support and prevention of the disease.

\section{REFERENCES}

1. Beck JK, Logan KJ, Hamm RM, Sproat SM, Musser KM, Everhart PD, McDermott HM, Copeland KC. Reimbursement for pediatric diabetes intensive 
case management: a model for chronic diseases?.

Pediatrics. 2004; 113: 47-50.

2. Svoren BM, Butler D, Levine BS, Anderson BJ, Laffel LM. Reducing acute adverse outcomes in youths with type 1 diabetes: a randomized, controlled trial. Pediatrics. 2003; 112: $914-922$.

3. The online community for kids, families and adults with diabetes, Family Support Network 